\title{
Neuronal generator patterns of olfactory event-related brain potentials in schizophrenia
}

\author{
JÜRGEN KAYSER, ${ }^{\mathrm{a}, \mathrm{b}}$ CRAIG E. TENKE, ${ }^{\mathrm{a}, \mathrm{b}}$ DOLORES MALASPINA, ${ }^{\mathrm{c}}$ CHRISTOPHER J. \\ KROPPMANN, ${ }^{\mathrm{a}}$ JENNIFER D. SCHALLER, ${ }^{\mathrm{a}}$ ANDREW DEPTULA, ${ }^{\mathrm{a}}$ NATHAN A. GATES, ${ }^{\mathrm{a}}$ \\ JILL M. HARKAVY-FRIEDMAN, ${ }^{\mathrm{b}}$ ROBERTO GIL, ${ }^{\mathrm{b}, \mathrm{d}}$ AND GERARD E. BRUDER ${ }^{\mathrm{a}, \mathrm{b}}$ \\ ${ }^{a}$ Division of Cognitive Neuroscience, New York State Psychiatric Institute, New York, New York, USA \\ ${ }^{\mathrm{b}}$ Department of Psychiatry, Columbia University College of Physicians \& Surgeons, New York, New York, USA \\ ${ }^{c}$ Department of Psychiatry, New York University School of Medicine, New York, New York, USA \\ ${ }^{\mathrm{d}}$ Division of Translational Imaging, New York State Psychiatric Institute, New York, New York, USA
}

\begin{abstract}
To better characterize neurophysiologic processes underlying olfactory dysfunction in schizophrenia, nose-referenced 30-channel electroencephalogram was recorded from 32 patients and 35 healthy adults (18 and 18 male) during detection of hydrogen sulfide (constant-flow olfactometer, $200 \mathrm{~ms}$ unirhinal exposure). Event-related potentials (ERPs) were transformed to reference-free current source density (CSD) waveforms and analyzed by unrestricted Varimax-PCA. Participants indicated when they perceived a high (10 ppm) or low (50\% dilution) odor concentration. Patients and controls did not differ in detection of high (23\% misses) and low (43\%) intensities and also had similar olfactory ERP waveforms. CSDs showed a greater bilateral frontotemporal N1 sink (305 ms) and mid-parietal P2 source $(630 \mathrm{~ms})$ for high than low intensities. N1 sink and P2 source were markedly reduced in patients for high intensity stimuli, providing further neurophysiological evidence of olfactory dysfunction in schizophrenia.
\end{abstract}

Descriptors: Olfaction, Schizophrenia, Event-related potential, ERP, Current source density, CSD, Principal components analysis, PCA, Surface Laplacian

The study of olfactory event-related potentials (OERP) requires a rapid onset of odor concentration (less than $50 \mathrm{~ms}$ rise time to $70 \%$ of maximum concentration; cf. Evans, Kobal, Lorig, \& Prah, 1993; Rombaux, Mouraux, Bertrand, Guerit, \& Hummel, 2006) and recording of olfactory responses that avoid concomitant trigeminal nerve stimulation (Lorig, 2000) and, depending on the research objective, potential confounds associated with active inhalation (Sobel et al., 1998; however, see Lorig, Matia, Peszka, \& Bryant, 1996, for a balanced discussion on the relative merits of active vs. passive breathing techniques). This became possible through the development of an olfactometer capable of producing a rapid pulse of odor in a constant air stream (Kobal, 1982, 2003; cf. Rombaux et al., 2006). Using an olfactometer,

The National Institute of Mental Health (NIMH) supported this research through grants MH066428, MH066597, and MH082393. We are grateful to Bruce Turetsky at the University of Pennsylvania for his help when we initially established an olfactory laboratory at New York State Psychiatric Institute. We thank Charles L. Brown, III, for developing a fine software for waveform plotting. Thanks are also due to Raymond Goetz and Deborah Goetz for their help with this project. We appreciate several constructive comments received during the review process by Tyler Lorig, Dean Salisbury, and two anonymous referees.

Address reprint requests to: Jürgen Kayser, New York State Psychiatric Institute, Division of Cognitive Neuroscience, Unit 50, 1051 Riverside Drive, New York, NY 10032, USA. E-mail: kayserj@pi.cpmc. columbia.edu researchers have begun to advance the knowledge in basic mechanisms of olfactory perception (Lorig, 2000). The clinical significance of OERPs is evident in that stimulation with vanillin or hydrogen sulfide $\left(\mathrm{H}_{2} \mathrm{~S}\right)$ yields no OERP components in anosmic patients (Kobal \& Hummel, 1998), and OERPs are closely associated with odor thresholds, odor discrimination, and odor identification (Lötsch \& Hummel, 2006). Although there has been some disagreement about the naming of peaks in the OERP waveforms, when using a combined lateral-inferior electroencephalogram (EEG) recording reference (i.e., linked ears or mastoids), healthy adults typically show as the first distinctive deflection a negative peak at vertex between 300 and $500 \mathrm{~ms}$, labeled N1 (e.g., Rombaux et al., 2006). This is followed by one or more positive deflections (e.g., P2, P3) peaking between 500 and 1500 ms (e.g., Pause, Sojka, Krauel, \& Ferstl, 1996; Turetsky et al., 2003). Although significantly delayed compared to other modalities (approximate N1 peak latencies range between 100 and $200 \mathrm{~ms}$ for auditory or visual stimuli) because of a longer transduction time at the olfactory receptor level (e.g., Rombaux et al., 2006), the N1 component may have similar modality-specific properties (Pause \& Krauel, 2000; Olofsson, Ericsson, \& Nordin, 2008). The olfactory pathway, however, unlike all other sensory systems, does not include a thalamic relay, and it is unknown to what extent different anatomical structures and cortical regions within the olfactory system (e.g., olfactory bulb, orbital prefrontal cortex; cf. Martzke, Kopala, \& Good, 1997) 
contribute to early olfactory components. Nevertheless, both N1 and P2 vary with external odor characteristics; for example, their amplitudes increase with greater odor concentration (e.g., Tateyama, Hummel, Roscher, Post, \& Kobal, 1998; Turetsky et al., 2003). In contrast, the P 3 component, as in other stimulus modalities, appears to change as a function of subjective significance, stimulus probability, and emotional valence of odors (Pause et al., 1996, 2003; see also Laudien, Kuster, Sojka, Ferstl, $\&$ Pause, 2006). However, a direct comparison of chemosensory, auditory, and visual N1, P2, and $\mathrm{P} 3$ peak deflections at midline sites $(\mathrm{Fz}, \mathrm{Cz}, \mathrm{Pz})$ revealed a clustering of chemosensory $\mathrm{P} 2$ and $\mathrm{P} 3$, which were, in turn, clustered with auditory and visual P3, suggesting that olfactory $\mathrm{P} 2$ may have functional properties typically attributed to P3 in other sensory systems (Olofsson et al., 2008). OERP components in healthy adults vary with age and gender, with younger adults or women having generally greater amplitude and shorter latency when compared to older adults or men (e.g., Covington, Geisler, Polich, \& Murphy, 1999; Morgan, Geisler, Covington, Polich, \& Murphy, 1999; Murphy et al., 2000; Olofsson \& Nordin, 2004; Stuck et al., 2006).

Very little is known about the current generators underlying the olfactory ERP components. Kettenmann, Hummel, Stefan, and Koba (1997), using magnetoencephalographic rather than EEG recordings, localized equivalent current dipoles or sources corresponding to $\mathrm{P} 1, \mathrm{~N} 1$, and $\mathrm{P} 2$ components between the superior temporal plane, the parainsular cortex, central parts of the insular, and the superior temporal sulcus. Furthermore, Daniels et al. (2001) found that patients with right-sided lesions, primarily affecting the temporal or parietal lobe, showed deficits in odor discrimination and decreased amplitudes of $\mathrm{P} 2$ and $\mathrm{P} 3$ at parietal scalp locations, independent of stimulation side (left or right nostril).

\section{Olfactory Deficits in Schizophrenia}

Evidence for olfactory dysfunction in schizophrenia has been reported in multiple studies using psychophysical measures of odor identification and detection thresholds. Studies have consistently found reduced ability to name or identify odors in schizophrenic patients compared to healthy controls, typically yielding large effect sizes (for a review, see Moberg et al., 1999). Findings for odor detection thresholds have been more mixed, with some studies reporting poorer odor thresholds in schizophrenia (Moberg et al., 1999) and others reporting normal or even superior olfactory acuity (Martzke et al., 1997; Moberg et al., 2006). Measuring unirhinal thresholds to n-butanol in 17 unmedicated patients and 17 well-matched healthy controls, Purdon and Flor-Henry (2000) found asymmetric thresholds in schizophrenia. Whereas controls revealed no nostril differences, patients had a greater deficit for the left compared to the right nostril, implicating a primarily left-lateralized impairment, given the predominantly ipsilateral afferent projections from the olfactory bulb to piriform cortex within the medial temporal lobe (e.g., Martzke et al., 1997; Moberg et al., 1999). Interestingly, this threshold asymmetry was reversed in another 10 patients after they received neuroleptic treatment, mostly because of left nostril improvements, which suggested that the effects of antipsychotic medication may differentially affect the two hemispheres (Purdon \& Flor-Henry, 2000).

Few studies, however, have been directed at the neurophysiologic processes underlying olfactory dysfunction in schizophrenia. In the first electrophysiologic study, Turetsky et al.
(2003) measured OERPs in 21 patients with schizophrenia and 20 healthy controls to three concentrations of $\mathrm{H}_{2} \mathrm{~S}$. Patients and controls did not differ significantly in ratings of the perceived intensity of the odors, but, nonetheless, patients had reduced N1 and $\mathrm{P} 2$ amplitudes, with the largest difference for the strongest odor intensity. Turetsky, Kohler, Gur, and Moberg (2008) also found similar reductions of $\mathrm{N} 1$ and $\mathrm{P} 2$ amplitude in first degree relatives of patients with schizophrenia, suggesting that this represents a vulnerability marker for this disorder. Using odorants of different hedonic value (i.e., rose-like phenethyl alcohol and rotten butter-like isobutyraldehyde), Pause, Hellmann, Goder, Aldenhoff, and Ferstl (2008) reported shorter peak latencies across several ERP components in nine schizophrenic compared to nine depressed and nine healthy men, but these effects were evidently most robust for N1 during the presentation of negative odors. Unfortunately, no ERP waveforms were included in this report, making it difficult to evaluate the exact meaning of these findings or to relate them to other studies.

\section{Methodological Issues in Olfactory ERP Research}

Following early recommendations (Evans et al., 1993), most OERP studies have relied on peak and latency measures of "prominent" deflections in selected OERP waveforms, mostly at vertex $(\mathrm{Cz})$ or neighboring midline $(\mathrm{Fz}, \mathrm{Pz})$ or lateral sites $(\mathrm{C} 3 / 4)$ and usually referenced to linked ear lobes or linked mastoids (e.g., Krüger, Frasnelli, Bräunig, \& Hummel, 2006; Lundström, Seven, Olsson, Schaal, \& Hummel, 2006; Murphy et al., 2000; Pause et al., 2003). The use of multichannel EEG montages has largely been limited to mapping ERP or $\mathrm{CSD}^{1}$ topographies (Laudien et al., 2006, 2008) or showing LORETA source localizations (Lorig, Rigdon, \& Poor, 2006). However, whereas inverse source localization algorithms, such as LORETA or BESA, have the potential for data simplification and clarification, these approaches provide genuinely model-dependent solutions that need to be cautiously considered, pending independent validation.

Statistical analyses have relied on ERP component measures employing a "region-of-interest" approach, in which the topographic ERP signal is reduced to a few spatially smeared sites, and is also subject to experimenter bias in the selection or grouping of electrodes (Kayser \& Tenke, 2005). Although the need to systematically identify the olfactory ERP component structure (i.e., how many major components with what temporal, spatial, and functional characteristics) has long been recognized (Lorig, 2000), only preliminary efforts have been made to date. ERP components are classically conceived as an electrophysiologic correlate of the underlying neuronal generators associated with information processes (cf. Kayser \& Tenke, 2003). This conceptual definition implies that an ERP component is characterized by (1) temporal (latency), (2) spatial (scalp topography), and (3) functional (task or condition) specificity (e.g., Donchin et al., 1977; Fabiani, Gratton, \& Coles, 2000). However, the identification and measurements of "obvious" peaks and troughs in the ERP waveforms as meaningful entities can be misleading. Specifying peaks in noisy waveforms (a problem not resolved but rather aggravated by using an automated computer algorithm)

\footnotetext{
${ }^{1}$ There appears to be considerable confusion about the meaning of sources and sinks and their relationship to ERP waveforms. CSD estimates represent the current flow entering (sinks) and leaving (sources) the scalp from the underlying brain tissue and are therefore equally important in characterizing neuronal generator activity. As such, these estimates must be fully compatible with the ERP topography from which they are derived in order to be of empirical or descriptive value.
} 
and determining area integration limits for deflections that invert and shift across scalp locations are subject to experimenter bias and raise questions of statistical independence, which will crucially affect their statistical analysis. Moreover, these ERP component measures depend directly on the recording reference, because the timing, topography, and amplitude of these ERP deflections will change with any other reference (e.g., Dien, 1998; Kayser, Fong, Tenke, \& Bruder, 2003), thereby affecting component interpretation (e.g., polarity, topography, generator). Thus, the definition and measurement of appropriate ERP components and the dependency of surface potentials on a reference location (e.g., linked ears or mastoids, nose, average) are two problems that have plagued ERP research (e.g., Kayser \& Tenke, 2003, 2005; Nunez \& Srinivasan, 2006; Tenke \& Kayser, 2005).

We have proposed that these limitations can be overcome without sacrificing information by combining current source density (CSD; surface Laplacian) and temporal principal components analysis (PCA) to identify relevant, data-driven components (Kayser \& Tenke, 2006a, 2006b; Kayser et al., 2006, 2010; Kayser, Tenke, Gates, \& Bruder, 2007; Kayser, Tenke, Gil, \& Bruder, 2009; Tenke et al., 2008; Tenke, Kayser, Stewart, \& Bruder, 2010). CSD provides a representation of current generators that underlie ERPs and represent the magnitude of radial current flow entering (sink) and leaving (source) the scalp (e.g., Nunez \& Srinivasan, 2006). CSD analysis is a reference-free technique (any EEG recording reference scheme will yield the same, unique CSD transform) that provides sharper topographies compared to those of scalp potentials while also reducing redundant contributions due to volume conduction (e.g., Tenke $\&$ Kayser, 2005). Often-raised concerns include the requirement of a high-density EEG montage for reliably computing CSDs, as well as their presumed insensitivity to deep sources. We have empirically addressed these concerns, demonstrating that no information is lost with the CSD transform when directly compared to the original ERPs, and deep or distributed sources, such as P3, are adequately and sufficiently represented (Kayser \& Tenke, 2006a). A low-density EEG montage may be as efficient as a dense electrode montage in summarizing CSD activity for group data, because group averages effectively impose a spatial low-pass filter to the data (Kayser \& Tenke, 2006b). In the specific context of olfactory ERPs, for which generators are presumably deep (i.e., with origins in olfactory, gustatory, or limbic structures), the corresponding fields and CSDs will be more diffuse at scalp, rendering a low-resolution surface Laplacian an advantage, rather than a liability. Thus, these conventional concerns have been overstated, and CSDs have not only been proven to be useful but may constitute an optimal analytic approach for many practical ERP applications. Compared to more complex EEG source localization methods (Michel et al., 2004), relying on surface Laplacian estimates as an analytic strategy is more conservative because it completely avoids additional (and unproven) biophysical assumptions (tissue conductivity and geometry, laminar orientation, number and independence of generators).

Temporal PCA is one of the most frequently used multivariate decomposition approaches for ERP data and has been repeatedly shown to be superior to more traditional ERP measures, for instance, revealing more robust $F$ statistics and better reliabilities (i.e., internal consistency and temporal stability) when directly compared with integrated time windows or baseline-to-peak measures (e.g., Beauducel, Debener, Brocke, \& Kayser, 2000; Kayser et al., 1997; Kayser, Tenke, \& Bruder, 1998). Often-cited limitations, such as misallocation of variance because of latency jitter, are not restricted to the use of temporal PCA but also affect traditional component measures and more severely (e.g., Beauducel \& Debener, 2003; Chapman \& McCrary, 1995; Donchin \& Heffley, 1978; Wood \& McCarthy, 1984). With careful consideration, temporal PCA can provide a concise and unbiased summary of ERP/CSD activity (Kayser \& Tenke, 2003, 2006a) associated with generator patterns underlying stimulus processing, even for slow and long-lasting components (e.g., Kayser et al., 2006), and could therefore provide an answer to the question of relative statistical independence between putative olfactory components (Lorig, 2000). Moreover, because the extracted CSD factors are independent of the recording reference, they have an unambiguous component polarity and topography.

A primary goal of this study was therefore to employ this new CSD-PCA approach for an improved characterization of OERPs (i.e., N1, P2) in schizophrenia patients and healthy adults. Following the findings of Turetsky et al. (2003), it was predicted that schizophrenia patients would show reduced N1 and $\mathrm{P} 2$ amplitudes (i.e., their CSD equivalents) when compared to healthy adults, and these OERP differences will be most evident at higher concentrations of $\mathrm{H}_{2} \mathrm{~S}$.

\section{Methods \\ Participants}

As part of a study of olfaction and social function in schizophrenia, 35 healthy adults (ages 18-61 years, $M \pm S D=$ $31.7 \pm 12.0$; 18 men; 6 smokers) without current or past psychopathology, neurological illness, or substance abuse (Nurnberger et al., 1994) were recruited for payment (US\$10/h) from the New York metropolitan area. These controls were compared to 17 inpatients and 15 outpatients at New York State Psychiatric Institute (ages $18-54$ years, $M \pm S D=33.3 \pm 9.6 ; 18$ men; 5 smokers) meeting DSM-IV (American Psychiatric Association, 1994) criteria for schizophrenia $(n=26 ; 15$ paranoid, 9 undifferentiated, 1 catatonic, 1 residual) or schizoaffective disorder ( $n=6 ; 3$ bipolar type, 3 depressive type). Diagnoses were based on clinical interviews by psychiatrists and trained psychologists and a semistructured interview (Nurnberger et al., 1994) including items from commonly used instruments (e.g., Andreasen 1983, 1984). Symptom ratings were obtained using the Positive and Negative Syndrome Scale (PANSS; Kay, Opler, \& Fishbein, 1992). The mean total Brief Psychiatric Rating Scale (BPRS) score available for 31 patients was $28.1 \pm 6.6$, with about equal scores for positive $(10.8 \pm 4.9)$ and negative $(11.7 \pm 3.9)$ symptoms (general $23.7 \pm 5.8$ ), indicating that patients were mildly disturbed. Mean age of onset available was $23.7 \pm 6.3$ years with an average illness duration of $9.8 \pm 8.9$ years. Most patients $(n=29)$ were treated with antipsychotic medications (9 aripriprazole, 7 risperidone, 5 olanzapine, 4 ziprasidone, 2 perphenazine, 1 clozapine, 1 quetiapine; chlorpromazine equivalents 25-800 mg/day; Woods, 2003).

All participants were right-handed (Oldfield, 1971; laterality quotient, controls vs. patients, $73.6 \pm 29.2$ vs. $84.0 \pm 18.3$ ). Patients tended to have less education than control participants, but this difference was of only marginal significance (14.2 \pm 2.7 vs. $15.5 \pm 1.7$ years), $F(1,63)=3.77, p=.06$. Participants were instructed to refrain from smoking on the day of test. OERP recording sessions were scheduled between 9 a.m. and 5 p.m. and lasted about $1.5 \mathrm{~h}$. Time of testing did not differ between groups, $F(1,63)<1.0$, n.s., thereby controlling for putative circadian in- 
fluences on OERP amplitudes (Nordin, Lötsch, Murphy, Hummel, \& Kobal, 2003). The experimental protocol had been approved by the institutional review board and was undertaken with the understanding and written consent of each participant.

\section{Stimuli and Procedure}

Participants were seated in an IAC sound-attenuated booth using a chin and forehead rest, with a video camera monitoring participants' compliance and behavior. While focusing on a fixation cross and breathing normally through the nose, ${ }^{2} \mathrm{H}_{2} \mathrm{~S}$ stimuli (10 ppm, Scott Speciality Gases, Plumsteadville, PA) at high (undiluted) and low (diluted to 50\%) concentrations were delivered to the left or right nostril by a constant-flow olfactometer (OM2s, Heinrich Burghart GmbH, Wedel, Germany) through a Teflon tube inserted approximately $1 \mathrm{~cm}$ into the naris. Stimulus duration was $200 \mathrm{~ms}$ (not more than $50 \mathrm{~ms}$ rise time according to manufacturer specification). For any given session, the air stream at the exit of the olfactometer had a constant flow rate (about $81 /$ $\min$ ), temperature (the measured range was $38^{\circ}-39^{\circ} \mathrm{C}$ at the olfactometers head to approximate $37^{\circ} \mathrm{C}$ body temperature in the nasal cavity), and relative humidity (above $80 \%$ ). Odors were presented in four blocks of 24 trials each, with a variable interstimulus interval (15-25 s). White noise of approximately $75 \mathrm{~dB}$ SPL was presented binaurally via Telephonics TDH-49P earphones to preclude hearing the switching valves. Participants responded as to whether they perceived a low or high intensity odor by raising their left or right hand, which was visually monitored and recorded by the experimenter. Therefore, the present paradigm consisted of an active odor intensity detection task, requiring conscious processing of and responding to perceived hydrogen sulfide stimuli. Because the time of odor stimulation was not cued, participants could fail to respond (miss). Nostril order and response hand assignment were counterbalanced across blocks and participants.

\section{Data Recording and Artifact Procedures}

All data recording and preprocessing closely followed the procedures detailed elsewhere (e.g., Kayser et al., 2007). Briefly, nose-referenced EEG (30 channels) and bipolar EOG activity were continuously recorded at 200 samples/s with a gain of $10 \mathrm{k}$ (5k horizontal, $2 \mathrm{k}$ vertical EOG) within $0.1-30 \mathrm{~Hz}(-6 \mathrm{~dB} /$ octave). Volume-conducted blink artifacts were removed from the raw EEG by spatial PCA. Recording epochs of $2000 \mathrm{~ms}$ ( 250 $\mathrm{ms}$ prestimulus baseline) were extracted off-line, tagged for $\mathrm{A} / \mathrm{D}$ saturation, and low-pass filtered at $20 \mathrm{~Hz}(-24 \mathrm{~dB} /$ octave). A reference-free approach identified residual artifacts on a channelby-channel and trial-by-trial basis (Kayser \& Tenke, 2006d). A trial was rejected if it contained artifact in more than eight channels; otherwise, artifactual data were replaced by spherical spline

\footnotetext{
${ }^{2}$ Although OERP studies typically trained participants to perform velopharyngeal closure as an active breathing technique to prevent intranasal respiratory airflow and interference during odor presentation, these potential benefits may be offset by the dual-task demands, resulting in divided attention that may alter odor processing. Comparisons of different breathing conditions with rather small sample sizes yielded conflicting results as to whether and how OERP amplitudes are affected (Lorig et al., 1996; Pause, Krauel, Sojka, \& Ferstl, 1999; Thesen \& Murphy, 2001). Given the likelihood of differences between healthy adults and schizophrenia patients in compliance with and capability of performing the velopharyngeal closure technique and that its associated systematic confounds (vigilance, attention) are more likely to affect odor detection and OERPs than the uncontrolled nasal air flow (cf. Laudien, Wencker, Ferstl, \& Pause, 2008; Mainland \& Sobel, 2006), a natural, spontaneous breathing condition seemed to be the preferred choice.
}

interpolation (Perrin, Pernier, Bertrand, \& Echallier, 1989) from artifact-free channels. These procedures for artifact detection and reduction were originally developed to optimize the signalto-noise ratio in problematic ERP recordings, such as those stemming from artifact-prone psychiatric samples, but these routines also help in reducing the problem of latency jitter in olfactory ERPs (Lorig, 2000).

Excluding trials on which the participant "missed" the odor, and disregarding the participant's high versus low intensity response, separate olfactory ERPs for high and low odor intensity were averaged from correctly detected, artifact-free trials using the entire 2-s epoch. To obtain more stable waveforms, ERPs were pooled across nostrils because of their blocked presentation order, and preliminary analyses did not reveal any effects of interest; furthermore, previous research has suggested that side of odor stimulation is of subordinate importance for measuring OERPs (e.g., Olofsson et al., 2006; Stuck et al., 2006). The mean number of trials $( \pm S D)$ used to compute OERP averages were $30.7 \pm 8.4$ and $23.1 \pm 8.9$ (high vs. low intensity, respectively) for healthy controls and $30.0 \pm 8.0$ and $23.6 \pm 8.5$ for patients. As expected, more trials entered into high than low intensity ERP averages, $F(1,63)=45.3, p<.0001$, but there were no differences between patients and controls. Visual inspections of the individual ERP waveforms also confirmed an acceptable signal-to-noise ratio for each participant. ERP waveforms were screened for electrolyte bridges (Tenke \& Kayser, 2001), low-pass filtered at $12.5 \mathrm{~Hz}$ ( $-24 \mathrm{~dB} /$ octave), and finally baseline corrected using the $100 \mathrm{~ms}$ preceding stimulus onset. ERPs were re-referenced to linked mastoids (TP9/10) for comparison to prior OERP studies using linked ear lobes or mastoids as reference.

\section{CSD Transform, Temporal PCA, and Statistical Analyses}

All OERP waveforms at each electrode were transformed into reference-free CSD estimates $\left(\mu \mathrm{V} / \mathrm{cm}^{2}\right.$ units; $10 \mathrm{~cm}$ head radius; 50 iterations; $m=4$; smoothing constant $\lambda=10^{-5}$ ) using a spherical spline surface Laplacian (Perrin et al., 1989). To determine their common sources of variance, CSD waveforms were submitted to temporal PCA derived from the covariance matrix, followed by unrestricted Varimax rotation of the covariance loadings (Kayser \& Tenke, 2003, 2006c). The input data matrix consisted of 401 variables (time interval -250 to $1750 \mathrm{~ms}$ ) and 4,154 observations stemming from 67 participants, two intensities, and 31 electrode sites, including the nose.

Data from two meaningful, high-variance CSD factors corresponding to $\mathrm{N} 1$ and $\mathrm{P} 2$ were submitted to repeated measures analysis of variance (ANOVA) with group (patients, controls) and gender (male, female) as between-subjects factors and odor intensity (high, low) as a within-subjects factor. The ANOVA designs also included subsets of lateral, homologous recording sites over both hemispheres at which PCA factor scores were largest and most representative of the associated CSD components (cf. Kayser \& Tenke, 2006a; Kayser et al., 2006), adding hemisphere and site as within-subjects factors to the design. However, because subsets were selected on the premise that they collectively represent sink or source activity targeted in these statistical analyses, site effects were of secondary interest and will not be reported.

It appears to be a fairly common, although incorrect, assumption that CSD methods necessarily identify equivalent current dipoles. Because multiple, overlapping generators with different geometries, time courses, and signal-to-noise ratios likely contribute to the ERP signal, it is not clear whether a 
prominent sink-source pattern represents opposite poles of a single dipole or several dipoles with different orientations. This uncertainty is not resolved by inverse models that identify putative current dipoles to simplify these generators patterns. In the case of the auditory N1, which consists of bilateral medial-central sinks and inferior-temporal sources having corresponding time courses and spanning the Sylvian fissure, thereby matching the orientation of the well-known underlying generator (e.g., Kayser $\&$ Tenke, 2006a, 2006b; Kayser et al., 2007, 2009), the ventral source may be larger than the central sink and subject to greater EMG noise from the neck. Another example would be a midline closed-field generator as described for a novelty vertex source (Tenke et al., 2010), where bilateral dipole orientations yield local field cancellations. The point is that CSD does not provide a single dipole measure, nor does it require one. For its quantification, we are adopting a pragmatic approach by analyzing CSD activity at regions or sites associated with distinct sinks or sources.

For analyses of the behavioral data, percentages of missed responses were submitted to a similar repeated measures ANOVA without the electrode factors. Sources of interactions and main effects were explored with simple effects (BMDP-4V; Dixon, 1992). When appropriate, Greenhouse-Geisser epsilon correction was used to compensate for violations of sphericity (e.g., Keselman, 1998). A conventional significance level $(p<.05)$ was applied for all effects.

\section{Results}

\section{Behavioral Data}

The mean percentages of $\mathrm{H}_{2} \mathrm{~S}$ stimuli that were missed $( \pm S D$ ) were $23.4 \pm 17.5$ and $44.9 \pm 19.3$ (high vs. low intensity, respectively) for healthy controls, and $22.5 \pm 16.1$ and $41.1 \pm 20.2$ for patients, yielding a highly significant main effect of odor intensity, $F(1,63)=77.2, p<.0001$, but no effects involving group, all $F(1,63)<1.0$, n.s.

\section{Average ERP and CSD Waveforms}

To the best of our knowledge, no complete ERP waveform topography for olfactory stimuli has yet been published, except for selected midline "topographies" (Fz, Cz, Pz), probably because of concerns about individual specificity (Lorig, 2000). By overlaying individual ERPs and CSDs, we established that the grand means accurately summarized temporal and spatial properties of the observed OERP components. Figure 1 compares the grand mean olfactory ERP and CSD component structure for all 67 participants at all 31 scalp locations (averaged across intensities). ${ }^{3}$ The OERP waveforms (solid gray lines) showed a typical negative-positive component sequence, including an N1 potential (approximate peak latency $300 \mathrm{~ms}$ ) believed to reflect initial sensory processing of olfactory stimuli followed by a $\mathrm{P} 2$ potential (600 ms), which is comparable to those reported in prior studies (Pause et al., 1996; Turetsky et al., 2003). By explicitly including the mastoid reference sites (TP9/10), however, it becomes obvious that recording sites along the reference-dependent isopotential line (e.g., T7/8, FT9/10, P9/10) showed little or no ERP activity. Thus, ERP activity at these sites is severely attenuated because of the arbitrary choice of the recording reference (Kayser

${ }^{3}$ The ERP/CSD component structure was highly comparable for healthy adults and schizophrenia patients (see Figures A1 and A2 in the supplementary material).
\& Tenke, 2006a, 2006b; Tenke \& Kayser, 2005). In contrast, the reference-free CSD waveforms (black dashed lines) identified robust sink activity at these sites, which was not compromised by the choice of reference. Although the observed N1 sink and P2 source in the CSD waveforms directly corresponded to the N1 and $\mathrm{P} 2$ potentials in the OERP waveforms, marked topographic distinctions were evident, particularly with respect to the frontotemporal N1 sink and lateral frontal sinks associated with the mid-parietal P2 source. ${ }^{4}$

$\mathrm{N} 1$ sink and $\mathrm{P} 2$ source amplitudes were greater to high- than low-intensity $\mathrm{H}_{2} \mathrm{~S}$ stimuli in both patients and healthy adults, further confirming their relationship to olfactory processing (Figure 2). Schizophrenia patients showed similar olfactory ERP and CSD waveforms when compared to controls, but their N1 sink and P2 source amplitudes were smaller.

\section{PCA Component Waveforms and Topographies}

The first four PCA factors effectively explained all of the systematic CSD variance ( $82.6 \%$ after rotation). The time courses of the factor loadings (Figure 3A) and the corresponding factor score topographies (Figure 3B) identified two factors corresponding to N1 sink (305 ms peak latency, lateral frontotemporal maximum) and $\mathrm{P} 2$ source (630 ms peak latency, mid-parietal maximum). Two later factors had a frontocentral (1015 ms) or parietal $(1750 \mathrm{~ms})$ midline sink maximum, suggesting a close correspondence to the response requirements in this task (i.e., raising left or right hand; cf. Kayser et al., 2007) and were therefore not further analyzed.

Both healthy adults and schizophrenia patients had bilateral N1 sinks for the high odor concentration over the lateral temporal sites (Figure 3B, top, first column) and a corresponding mid-frontopolar source. Similarly, both controls and patients showed a medial parietal P2 source topography to both low and high odor concentrations, with current sinks maximal over lateral frontotemporal regions (Figure 3B, bottom, Columns 1 and 2). The reduced amplitude of the N1 sink and P2 source in patients was most evident to the high concentration of $\mathrm{H}_{2} \mathrm{~S}$.

\section{Repeated Measures ANOVA of PCA Factor Scores}

N1 sink. At lateral centrotemporal sites (T7/8, C3/4, FC5/6, $\mathrm{CP} 5 / 6$ ) for factor 305 , there was a highly significant main effect of intensity, $F(1,63)=131.7, p<.0001$, confirming the presence of the N1 sink for high but not low odor intensities (Figure 3B, top; for detailed ANOVA means, see supplementary Table A1). A significant Group $\times$ Intensity interaction, $F(1,63)=6.11, p=.02$, resulted from a reduction of $\mathrm{N} 1$ sink amplitude in schizophrenia for high- but not low-intensity stimuli: simple group main effects at high intensity, $F(1,63)=5.87, p=.02$, at low intensity, $F(1,63)$ $<1.0$, n.s. There were also a significant interactions of Group $\times$ Gender, $F(1,63)=4.15, p=.05$, and of Group $\times$ Gender $\times$ Intensity, $F(1,63)=4.87, p=.03$, which originated from greater high intensity N1 sinks for healthy women compared to healthy men $(M \pm S D,-1.42 \pm 1.57$ vs. $-0.97 \pm 0.92)$, with patients showing the opposite gender effect $(-0.51 \pm 0.95$ vs. $-0.95 \pm 1.02)$; simple Group $\times$ Gender interaction effects, at high intensity, $F(1,63)=5.27, \quad p=.03$, at low intensity, $F(1,63)<1.0$, n.s.

\footnotetext{
${ }^{4}$ Animated ERP (linked-mastoids reference) and CSD topographies comparing groups and intensities can be obtained at URL http:// psychophysiology.cpmc.columbia.edu/oerp2008.html.
} 


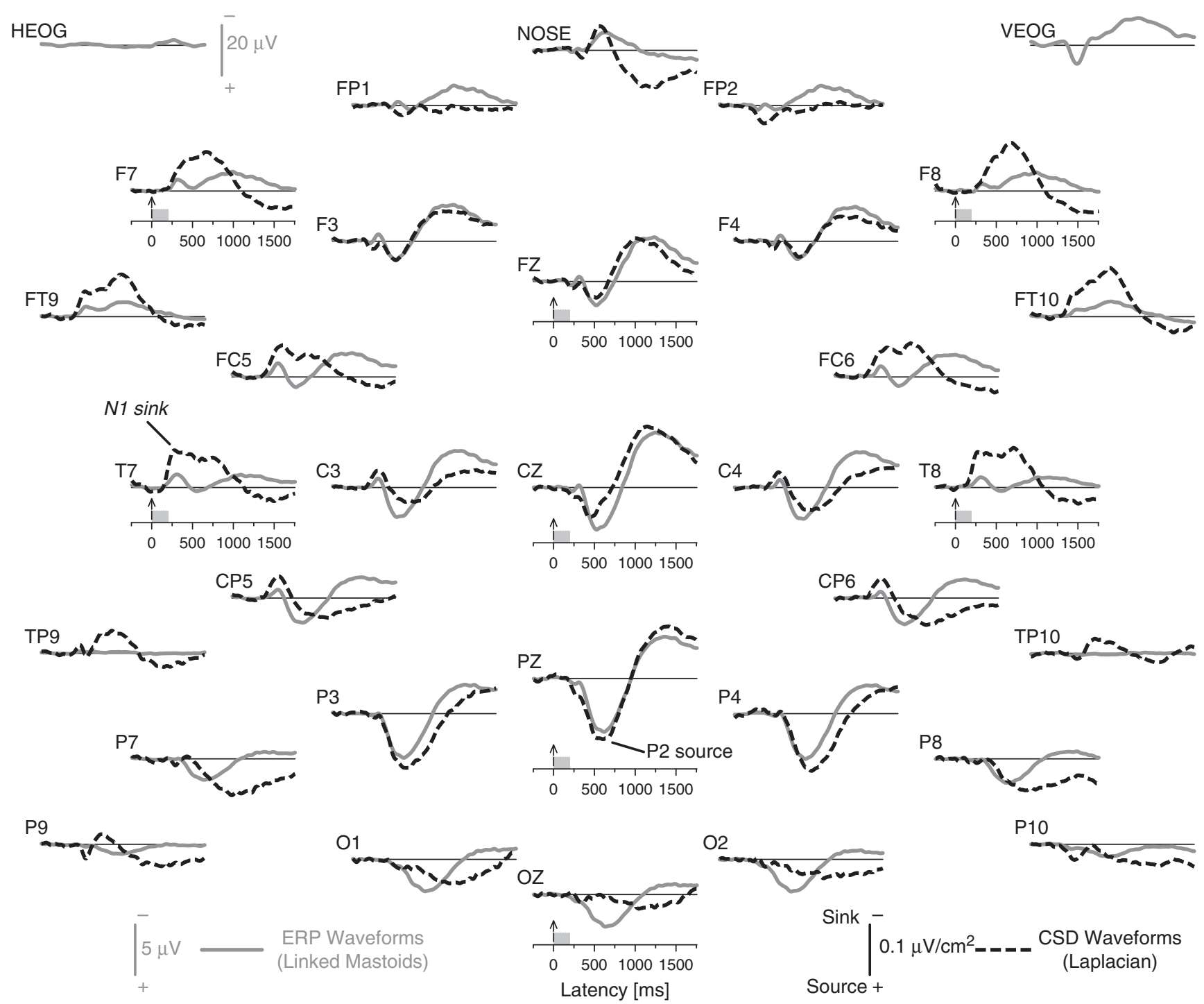

Figure 1. Grand mean olfactory ERPs referenced to linked mastoids and reference-free CSD waveforms for the total sample $(N=67)$ at all 31 recording sites (averaged across intensity). Horizontal and vertical electrooculograms (EOG), which are shown at a smaller scale before blink correction, indicate no eye artifact concerns. Two prominent CSD components are labeled at sites T7 (N1 sink) and Pz (P2 source), where they closely corresponded to their ERP counterparts.

The analysis for the frontopolar source (Fpl/2) accompanying the bilateral centrotemporal sinks for factor 305 revealed highly significant intensity, $F(1,63)=27.2, p<.0001$, and Group $\times$ Intensity effects, $F(1,63)=7.71, p=.007$, stemming from a greater high-larger-than-low-intensity amplitude difference for controls compared with patients (Figure 3B, top). Across groups, this source was also greater over the right than left frontopolar site: hemisphere main effect, $F(1,63)=4.28$, $p=.04$.

P2 source. At medial-lateral centroparietal sites (P3/4, P7/8, $\mathrm{CP} 5 / 6, \mathrm{C} 3 / 4)$ for factor 630 , there was also a highly significant main effect of intensity, $F(1,63)=74.5, p<.0001$, stemming from a greater $\mathrm{P} 2$ source for high than low odor concentration (Figure 3B, bottom; for detailed ANOVA means, see supplementary Table A2). A significant group main effect, $F(1,63)$ $=6.48, p=.01$, and a highly significant Group $\times$ Intensity interaction, $F(1,63)=14.0, p=.0004$, indicated smaller $\mathrm{P} 2$ source in patients compared to healthy adults, which was significant for high (simple group main effect, $F(1,63)=16.3, p=.0001$ ) but not low intensity stimuli, $F(1,63)<1.0$, n.s. A significant hemisphere main effect, $F(1,63)=5.99, p=.02$, resulted from rightlarger-than-left P2 source across groups. A greater P2 source in women compared with men for both controls $(M \pm S D$, $0.71 \pm 0.94$ vs. $0.40 \pm 0.81)$ and patients $(0.38 \pm 0.77$ vs. $0.31 \pm 0.72)$ yielded a significant gender main effect, $F(1,63)=5.41, p=.02$.

The analysis for the lateral frontotemporal sinks (FT9/10, F7/ 8 ) accompanying the parietal P2 for factor 630 revealed a highly significant main effects of intensity, $F(1,63)=16.8, p=.0001$, hemisphere, $F(1,63)=13.2, p=.0006$, and gender, $F(1,63)=14.1$, $p=.0004$, which resulted from greater sinks for high compared to low intensity and right-larger-than-left hemisphere sinks (Figure $3 \mathrm{~B}$, bottom), and greater sinks in women than men $(M \pm S D$, $-0.97 \pm 0.89$ vs. $-0.47 \pm 0.84)$. However, there were no significant effects involving group. 

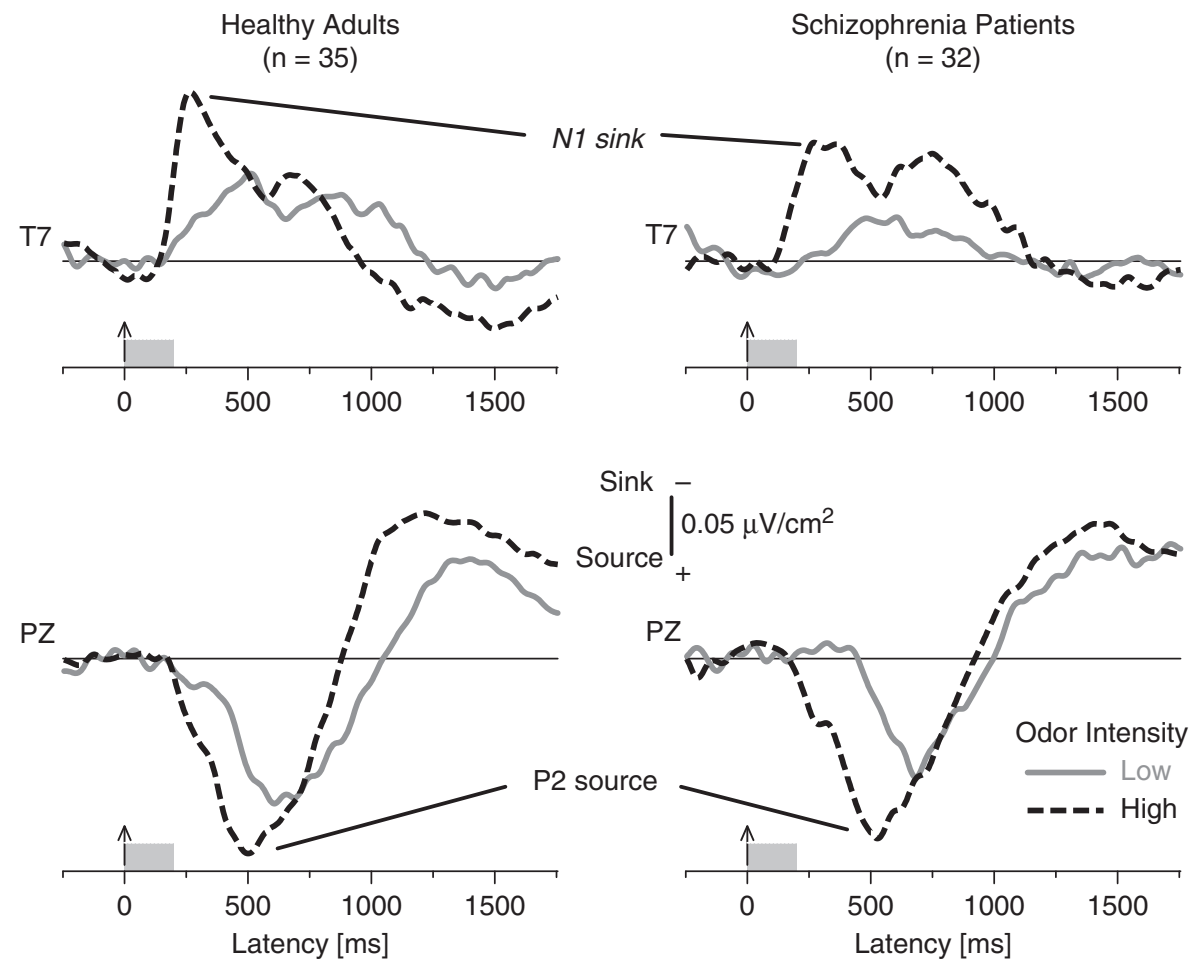

Figure 2. Grand mean olfactory CSDs for 35 healthy adults and 32 schizophrenia patients comparing low- and high-intensity $\mathrm{H}_{2} \mathrm{~S}$ stimuli at sites $\mathrm{T} 7$ and Pz.

\section{Discussion}

The application of the CSD-PCA approach identified factors corresponding to the $\mathrm{N} 1$ and $\mathrm{P} 2$ potentials, which have been consistently observed in OERP studies (Lorig, 2000; Pause \& Krauel, 2000). Schizophrenia patients and healthy controls showed a prominent N1 sink over frontotemporal sites and a corresponding mid-frontopolar source. This topography is fully compatible with postulated generators within the medial temporal lobe and/or basal cortical regions (e.g., orbital frontal cortex; cf. Martzke et al., 1997). In addition, the observed N1 sink topography was distinctly unique, that is, it did not match generator patterns previously described for early visual (e.g., Kayser et al., 2006, 2007, 2009) or auditory components (e.g., Kayser \& Tenke, 2006a, 2006b; Kayser et al., 2007, 2009; Tenke et al., 2008, 2010), which strongly suggests that the underlying neuronal activity may indeed reflect an early, modality-specific processing stage during odor perception. In contrast, the P2 source had a mid-parietal topography, with current sinks over lateral frontotemporal sites, which is compatible with the notion of a close association of olfactory $\mathrm{P} 2$ with a classical P $3 \mathrm{~b}$ potential (e.g., Lorig, 2000; Olofsson et al., 2008). Moreover, the observed P2 source topography was highly similar to P3 source topographies repeatedly found during working and recognition memory paradigms using visual or auditory word stimuli (e.g., Kayser et al., 2006, 2007, 2009, 2010) or during auditory oddball paradigms (e.g., Kayser \& Tenke, 2006a, 2006b; Tenke et al., 2010). The corresponding generators of olfactory P2 are therefore consistent with those of P3 in other modalities, rather than with regions unique to olfaction. Although this agrees with the P3-like interpretation of the $\mathrm{P} 2$ source, the likeness of the olfactory $\mathrm{N} 1$ sink to N1 activity observed for other modalities may be challenged by the suggestion that the olfactory bulbs themselves may be closer homologs to the primary sensory cortices of other modalities than are piriform cortex and related olfactory cortical regions (Haberly, 2001). In this scenario, it is unlikely that neuronal activity of primary olfactory processing, equivalent to calcarine or Heschl's gyrus activation within the visual or auditory pathways, will propagate to scalp and may therefore not register as an ERP component. Another consideration is that the completely different organization of the olfactory system (e.g., lack of thalamocortical projections, afferent and efferent projections of primary sensory cortex vs. limbic cortex) makes a homology with $\mathrm{N} 1$ from other modalities improbable. Rather, olfactory N1 sink activity peaking around $300 \mathrm{~ms}$ may instead reflect functional activation of secondary olfactory regions, including piriform cortex, analogous to inferior-temporal visual association cortex (see Figure 13 in Haberly, 2001). The implication of this proposition is that N1 sink could be regarded as an olfactory N2, analogous to an auditory or visual N2. In this case, the olfactory $\mathrm{N} 1$ should be associated with stimulus categorization and classification, and the sequence of olfactory $\mathrm{N} 1$ sink and $\mathrm{P} 2$ source in the present odor detection paradigm would be the olfactory equivalent of an N2/P3 complex typically observed during many ERP paradigms, including an oddball task. Although it is not impossible that an olfactory $\mathrm{N} 1$ originates in basal cortex, and the observed bilateral temporal N1 sink pattern is not necessarily inconsistent with this assumption, the preferential access of olfaction to evaluative (also limbic) processes would suggest a functional correlate that is consistent with N2-like categorization.

The N1 sink and P2 source were greater to high than low concentrations of $\mathrm{H}_{2} \mathrm{~S}$, which is in accord with prior studies (Stuck et al., 2006; Turetsky et al., 2003) and supports their relation to olfactory processing. It is also compatible with the idea the N1 sink reflects N2-like categorization processes, although future studies have to pursue this hypothesis with a more ap- 
A CSD Factor Loading Waveforms

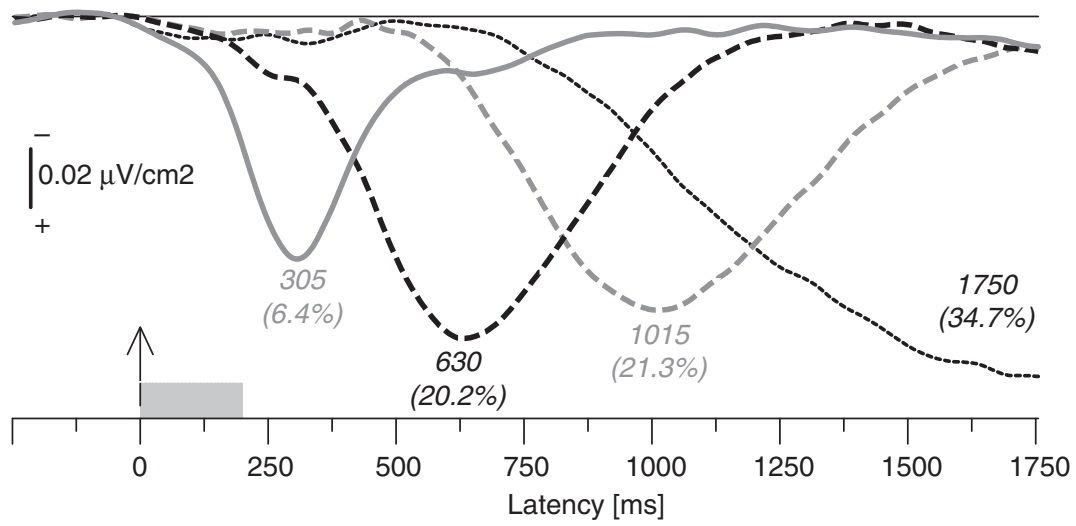

B
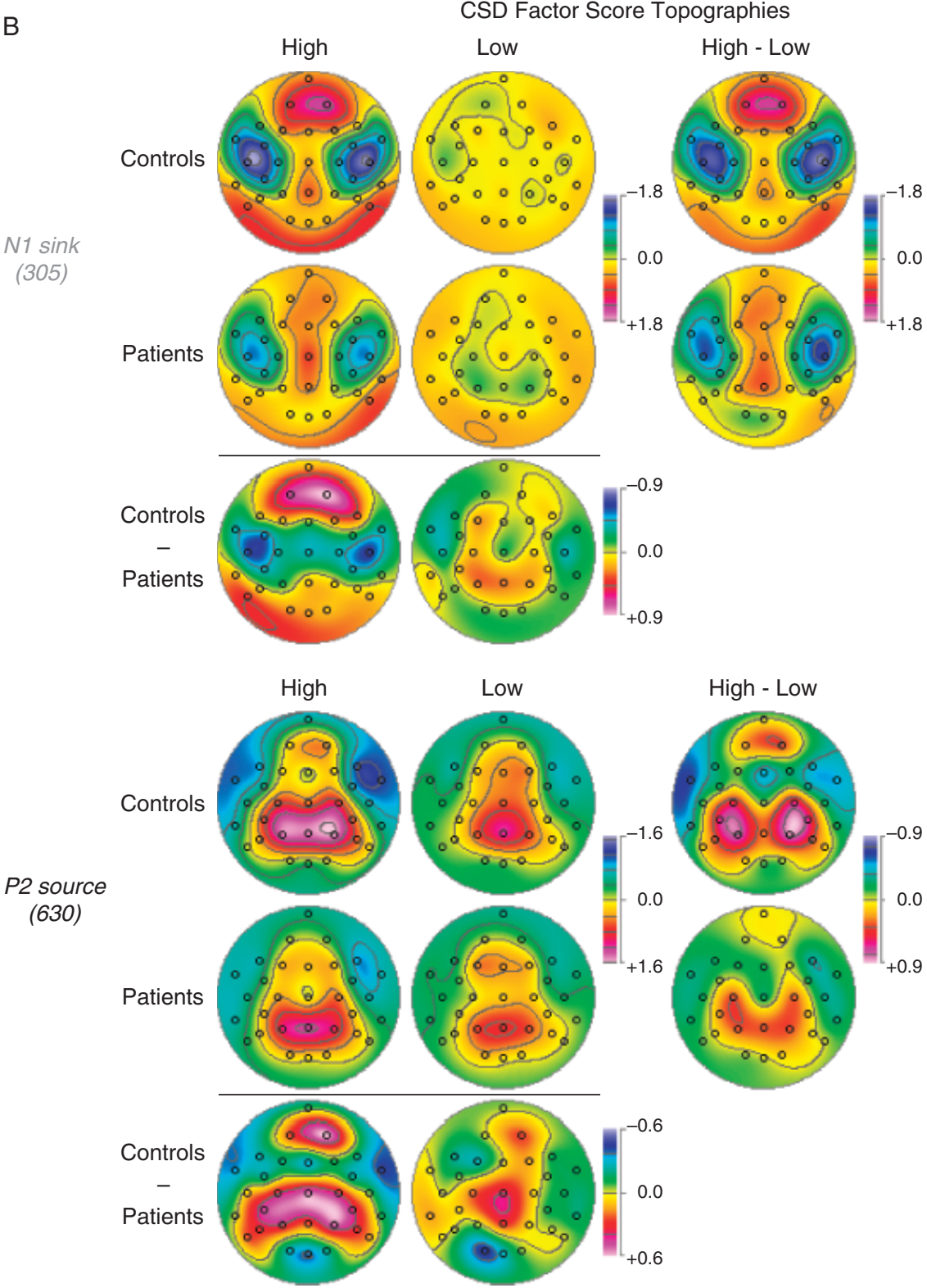

Figure 3. (a) Factor loadings of the first four PCA factors (labels indicate peak latency [with variance explained]) extracted from olfactory CSD waveforms $(N=67)$. (b) CSD factor score topographies corresponding to N1 sink (top) and P2 source (bottom) for 35 healthy controls and 32 schizophrenia patients comparing low- and high-intensity $\mathrm{H}_{2} \mathrm{~S}$ stimuli. Margins show difference topographies for intensity (high minus low) and group (controls minus patients). 
propriate design, for instance, by including a broader parametric manipulation or different odors. Notably, as the current data were based on 12-16 trials per intensity level, it is evident that viable and meaningful olfactory ERP/CSD averages can be obtained with a relatively small number of trials.

Schizophrenic patients had reduced N1 sink and P2 source amplitudes to the higher concentration of $\mathrm{H}_{2} \mathrm{~S}$, replicating the findings of Turetsky et al. (2003). The reduced OERPs in schizophrenia patients were present in the absence of behavioral differences between patients and controls. Schizophrenia patients showed considerable success in performing the olfaction task, and their behavioral performance was on a par with that for healthy controls. This indicates that the OERP reductions in schizophrenia are not due to a failure to attend to stimuli or overall poorer task performance. Instead, it is more parsimonious to presume that the OERP differences reflect an abnormality in obligatory processing of odors in cortical regions related to olfaction. Similarly, the lack of an association of olfactory identification and neurocognitive test performance (Continuous Performance Test and Wisconsin Card Sorting Test) has been cited as evidence that reduced olfactory function in schizophrenia is not secondary to deficits in attention or executive function (Seidman et al., 1997). It still remains to be demonstrated, however, whether the OERP deficits in schizophrenia are specific to olfactory processing or stem from a frontotemporal dysfunction that affects ERPs in multiple modalities. Given our N2-like interpretation of the olfactory $\mathrm{N} 1$ sink, its marked reduction in schizophrenia is in striking accordance with ERP evidence documenting profound reductions of $\mathrm{N} 2$ amplitudes across processing modalities and paradigms (e.g., Alain, Bernstein, He, Cortese, \& Zipursky, 2002; Alain, Cortese, Bernstein, He, \& Zipursky, 2001; Bruder et al., 1998, 1999; Kayser et al., 1999, 2001, 2009; O’Donnell et al., 1993; Umbricht, Bates, Lieberman, Kane, \& Javitt, 2006).

The reduction of N1 sink over lateral temporal lobe sites and P2 source over medial parietal sites in schizophrenia patients was bilateral and not dependent on hemisphere. However, the P2 source and lateral frontotemporal sink, as well as the frontopolar source accompanying N1, were greater over right than left hemisphere sites across both patients and healthy adults. In this regard, brain-damaged patients with lesions to the temporal lobe or orbitofrontal cortex, particularly in the right hemisphere, showed deficits in higher-order odor processing (Jones-Gotman \& Zatorre, 1993), and patients with right-sided lesions of the frontal or temporal lobe showed decreased amplitudes of P2 and P3 potentials to odors at parietal sites (Daniels et al., 2001). Positron emission tomography (PET) studies measuring regional cerebral blood flow (rCBF) in healthy adults judging the pleasantness and intensity of odors have provided additional evidence supporting the important role of right orbitofrontal cortex in olfactory processing (Zatorre, Jones-Gotman, \& Rouby, 2000). Malaspina et al. (1998) measured rCBF (using SPECT scans) in 6 schizophrenia patients and 7 controls during an odor identification task, and the patients showed hypometabolism in right cortical regions, including the inferior frontal area, superior temporal lobe, and supramarginal and angular gyrus. A review of hemodynamic evidence of lateralized olfactory processes suggested that olfactory stimuli differentially activate left or right brain regions, including medial temporal lobe and orbitofrontal cortex, but the inconsistent nature of this asymmetry has prompted suggestions that hemispheric differences depend on the cognitive or emotional processing demands (Royet \& Plailly, 2004). Also, a study of laterality of OERPs during monorhinal stimulation with amyl acetate in 28 healthy adults found generally larger N1/P2 amplitudes for left than right nostril stimulation and at left than right hemisphere sites for left nostril stimuli (Olofsson et al., 2006). A related issue that has attracted less attention in this context is the potential confound of blocking left or right stimulus presentations as mandated by use of an olfactometer, such as the one used in the current study. Blocked unilateral odor presentations could lead to corresponding contralateral shifts in attention (cf. Kinsbourne, 1970), which may interfere with the predominantly ipsilateral organization of the olfactory system (e.g., Martzke et al., 1997). Thus, additional research is needed to clarify the nature of hemispheric asymmetries of OERPs and their relation to stimulus and task demands.

A gender effect was found for the N1 sink that differed across groups. Namely, healthy women showed greater N1 for the high concentration of $\mathrm{H}_{2} \mathrm{~S}$ compared to healthy men, whereas schizophrenia patients showed the opposite gender effect. P2 also showed a gender effect, with women showing greater source and sink activity than men, but this was not dependent on group. Although Kopala, Clark, and Hurwitz (1989) originally reported that men with schizophrenia had greater olfactory impairment than women for smell identification, more recent studies by this and other groups have not replicated this gender effect (Kopala, Good, Martzke, \& Hurwitz., 1995; Moberg et al., 1999; Seidman et al., 1997). Although we know of no reports examining gender differences in OERPs of schizophrenia patients, Becker et al. (1993) found larger P1/N1 and N1/P2 amplitudes for vanillin and $\mathrm{H}_{2} \mathrm{~S}$ odorants in women compared to men in a sample of healthy and psychosis-prone subjects (i.e., gender differences were unaffected by group classification), and Stuck et al. (2006) also found larger $\mathrm{P} 2$ amplitudes to $\mathrm{H}_{2} \mathrm{~S}$ in healthy women than men. Lundström and Hummel (2006), measuring ERPs of healthy adults to peppermint, which activates both olfactory and trigeminal systems, did not find a gender effect for P2 amplitude but did report that women had larger amplitude of N1 over the left than right hemisphere, whereas men had larger P1 amplitude over the right than left hemisphere. Although these studies suggest possible gender effects in OERPs, the extent to which they differ in schizophrenia patients and healthy adults needs further study.

There are several limitations of this study that should be noted. First, participants responded to the odors by raising their hand. Although this is unlikely to have affected the earlier OERP components (N1 or P2), it may have interfered with the measurement of later components (cf. Kayser et al., 2007). Second, subjects were not cued as to the time of odor presentation, and there was also no control of their breathing technique (i.e., natural breathing through mouth and nose). Although this could well have increased the variability of OERP measurements, leading to overall reduced OERP amplitudes compared to controlled breathing procedures (cf. Pause et al., 1999; Thesen \& Murphy, 2001), there is no reason to believe that it would have differentially affected the schizophrenia patients and healthy adults. Third, OERPs were measured only to the unpleasant smelling odor of $\mathrm{H}_{2} \mathrm{~S}$. One of the distinguishing features of olfactory stimuli is their strong affective associations and the brain regions mediating olfaction overlap with those mediating emotional processing. The extent to which deficits in OERPs in schizophrenia are related to the emotional valence of the odors is an important issue for future research (cf. Pause et al., 2008). Fourth, although the lack of antipsychotic medication control is 
also a limitation, there is little evidence that medication status is related to performance on psychophysical measures of olfactory function (Moberg et al., 1999); however, the reported relation of neuroleptic treatment to asymmetrical olfactory thresholds (Purdon \& Flor-Henry, 2000) may imply a more complex moderating influence of drug treatment on olfactory function. Lastly, this study compared schizophrenia patients and healthy controls, but there were marked individual differences in the OERPs among patients, which raises the possibility that only a subgroup of schizophrenia patients have OERP deficits. Further study should be given to examining clinical, neurophysiological, and neuroanatomical correlates of olfactory deficits in schizophrenia.

Apart from replicating the original findings of Turetsky et al. (2003) with a considerably larger sample, the current study ad- vances olfactory ERP research by providing a complete, comparative topographic analysis of reference-independent current source densities underlying reference-dependent surface potentials. The PCA-based summary of orthogonal variance contributions identified a distinct, bilateral temporal N1 sink that appears to be unique to olfactory stimuli. This PCA-CSD component has a subtle ERP counterpart with similar topography that has not yet been reported in the literature, presumably because the common choice of a linked-mastoids reference attenuates the visibility of this topographic effect. In contrast, the topography of P2 source, the second prominent PCA-CSD component, was found to be highly similar to P3 source topographies observed for other stimulus modalities. The topographic CSD findings and insights for olfactory $\mathrm{N} 1$ and $\mathrm{P} 2$ are unique and may help stimulate methodological and theoretical advancements in the field.

\section{REFERENCES}

Alain, C., Bernstein, L. J., He, Y., Cortese, F., \& Zipursky, R. B. (2002). Visual feature conjunction in patients with schizophrenia: An eventrelated brain potential study. Schizophrenia Research, 57, 69-79.

Alain, C., Cortese, F., Bernstein, L. J., He, Y., \& Zipursky, R. B. (2001). Auditory feature conjunction in patients with schizophrenia. Schizophrenia Research, 49, 179-191.

American Psychiatric Association. (1994). Diagnostic and Statistical Manual of the Mental Disorders (4th ed). Washington, DC: American Psychiatric Association.

Andreasen, N. C. (1983). The Scale for the Assessment of Negative Symptoms ( SANS). Iowa City: The University of Iowa.

Andreasen, N. C. (1984). The Scale for the Assessment of Positive Symptoms (SAPS). Iowa City: The University of Iowa.

Beauducel, A., \& Debener, S. (2003). Misallocation of variance in eventrelated potentials: Simulation studies on the effects of test power, topography, and baseline-to-peak versus principal component quantifications. Journal of Neuroscience Methods, 124, 103-112.

Beauducel, A., Debener, S., Brocke, B., \& Kayser, J. (2000). On the reliability of augmenting/reducing: Peak amplitudes and principal components analysis of auditory evoked potentials. Journal of Psychophysiology, 14, 226-240.

Becker, E., Hummel, T., Piel, E., Pauli, E., Kobal, G., \& Hautzinger, M. (1993). Olfactory event-related potentials in psychosis-prone subjects. International Journal of Psychophysiology, 15, 51-58.

Bruder, G., Kayser, J., Tenke, C., Amador, X., Friedman, M., Sharif, Z., et al. (1999). Left temporal lobe dysfunction in schizophrenia: Eventrelated potential and behavioral evidence from phonetic and tonal dichotic listening tasks. Archives of General Psychiatry, 56, 267-276.

Bruder, G., Kayser, J., Tenke, C., Rabinowicz, E., Friedman, M., Amador, X., et al. (1998). The time course of visuospatial processing deficits in schizophrenia: An event-related brain potential study. Journal of Abnormal Psychology, 107, 399-411.

Chapman, R. M., \& McCrary, J. W. (1995). EP component identification and measurement by principal components analysis. Brain and Cognition, 27, 288-310.

Covington, J. W., Geisler, M. W., Polich, J., \& Murphy, C. (1999). Normal aging and odor intensity effects on the olfactory event-related potential. International Journal of Psychophysiology, 32, 205-214.

Daniels, C., Gottwald, B., Pause, B. M., Sojka, B., Mehdorn, H. M., \& Ferstl, R. (2001). Olfactory event-related potentials in patients with brain tumors. Clinical Neurophysiology, 112, 1523-1530.

Dien, J. (1998). Issues in the application of the average reference: Review, critiques, and recommendations. Behavior Research Methods, Instruments, \& Computers, 30, 34-43.

Dixon, W. J. (Ed.). (1992). BMDP Statistical Software Manual: to Accompany the 7.0 Software Release. Berkeley, CA: University of California Press.

Donchin, E., Callaway, R., Cooper, R., Desmedt, J. E., Goff, W. R., Hillyard, S. A., et al. (1977). Publication criteria for studies of evoked potentials (EP) in man. In J. E. Desmedt (Ed.), Progress in clinical neurophysiology: Vol. 1. Attention, voluntary contraction and eventrelated cerebral potentials (pp. 1-11). Basel: Karger.
Donchin, E., \& Heffley, E. F. (1978). Multivariate analysis of eventrelated potential data: A tutorial review. In D. A. Otto (Ed.), Multidisciplinary perspectives in event-related brain potential research. Proceedings of the fourth international congress on event-related slow potentials of the brain (EPIC IV), Hendersonville, NC, April 4-10, 1976 (pp. 555-572). Washington, DC: The Office.

Evans, W. J., Kobal, G., Lorig, T. S., \& Prah, J. D. (1993). Suggestions for collection and reporting of chemosensory (olfactory) event-related potentials. Chemical Senses, 18, 751-756.

Fabiani, M., Gratton, G., \& Coles, M. G. H. (2000). Event-related brain potentials: Methods, theory, and applications. In J. T. Cacioppo, L. G. Tassinary, \& G. G. Bernston (Eds.), Handbook of psychophysiology (2nd ed, pp. 53-84). Cambridge, UK: Cambridge University Press.

Haberly, L. B. (2001). Parallel-distributed processing in olfactory cortex: New insights from morphological and physiological analysis of neuronal circuitry. Chemical Senses, 26, 551-576.

Jones-Gotman, M., \& Zatorre, R. J. (1993). Odor recognition memory in humans: Role of right temporal and orbitofrontal regions. Brain and Cognition, 22, 182-198.

Kay, S. R., Opler, L. A., \& Fishbein, A. (1992). Positive and negative syndrome scale (PANSS) rating manual. Toronto, Canada: Multihealth System Inc.

Kayser, J., Bruder, G. E., Friedman, D., Tenke, C. E., Amador, X. F., Clark, S. C., et al. (1999). Brain event-related potentials (ERPs) in schizophrenia during a word recognition memory task. International Journal of Psychophysiology, 34, 249-265.

Kayser, J., Bruder, G. E., Tenke, C. E., Stuart, B. K., Amador, X. F., \& Gorman, J. M. (2001). Event-related brain potentials (ERPs) in schizophrenia for tonal and phonetic oddball tasks. Biological Psychiatry, 49, 832-847.

Kayser, J., Fong, R., Tenke, C. E., \& Bruder, G. E. (2003). Event-related brain potentials during auditory and visual word recognition memory tasks. Cognitive Brain Research, 16, 11-25.

Kayser, J., \& Tenke, C. E. (2003). Optimizing PCA methodology for ERP component identification and measurement: Theoretical rationale and empirical evaluation. Clinical Neurophysiology, 114, 23072325.

Kayser, J., \& Tenke, C. E. (2005). Trusting in or breaking with convention: Towards a renaissance of principal components analysis in electrophysiology. Clinical Neurophysiology, 116, 17471753.

Kayser, J., \& Tenke, C. E. (2006a). Consensus on PCA for ERP data, and sensibility of unrestricted solutions. Clinical Neurophysiology, 117, 703-707.

Kayser, J., \& Tenke, C. E. (2006b). Electrical distance as a reference-free measure for identifying artifacts in multichannel electroencephalogram (EEG) recordings. Psychophysiology, 43, S51.

Kayser, J., \& Tenke, C. E. (2006c). Principal components analysis of Laplacian waveforms as a generic method for identifying ERP generator patterns: I. Evaluation with auditory oddball tasks. Clinical Neurophysiology, 117, 348-368. 
Kayser, J., \& Tenke, C. E. (2006d). Principal components analysis of Laplacian waveforms as a generic method for identifying ERP generator patterns: II. Adequacy of low-density estimates. Clinical Neurophysiology, 117, 369-380.

Kayser, J., Tenke, C. E., \& Bruder, G. E. (1998). Dissociation of brain ERP topographies for tonal and phonetic oddball tasks. Psychophysiology, 35, 576-590.

Kayser, J., Tenke, C. E., Gates, N. A., \& Bruder, G. E. (2007). Reference-independent ERP old/new effects of auditory and visual word recognition memory: Joint extraction of stimulus- and response-locked neuronal generator patterns. Psychophysiology, 44, 949-967.

Kayser, J., Tenke, C. E., Gates, N. A., Kroppmann, C. J., Gil, R. B., \& Bruder, G. E. (2006). ERP/CSD indices of impaired verbal working memory subprocesses in schizophrenia. Psychophysiology, 43, 237252.

Kayser, J., Tenke, C. E., Gil, R. B., \& Bruder, G. E. (2009). Stimulusand response-locked neuronal generator patterns of auditory and visual word recognition memory in schizophrenia. International Journal of Psychophysiology, 73, 186-206.

Kayser, J., Tenke, C. E., Kroppmann, C. J., Fekri, S., Alschuler, D. M., Gates, N. A., et al. (2010). Current source density (CSD) old/new effects during recognition memory for words and faces in schizophrenia and in healthy adults. International Journal of Psychophysiology, 75, 194-210.

Kayser, J., Tenke, C., Nordby, H., Hammerborg, D., Hugdahl, K., \& Erdmann, G. (1997). Event-related potential (ERP) asymmetries to emotional stimuli in a visual half-field paradigm. Psychophysiology, $34,414-426$.

Keselman, H. J. (1998). Testing treatment effects in repeated measures designs: An update for psychophysiological researchers. Psychophysiology, 35, 470-478.

Kettenmann, B., Hummel, C., Stefan, H., \& Kobal, G. (1997). Multiple olfactory activity in the human neocortex identified by magnetic source imaging. Chemical Senses, 22, 493-502.

Kinsbourne, M. (1970). The cerebral basis of lateral asymmetries in attention. Acta Psychologica, 33, 193-201.

Kobal, G. (1982). A new method for determination of the olfactory and the trigeminal nerve's dysfunction: Olfactory (OEP) and chemical somatosensensory (CSEP) evoked potentials. In A. Rothenberger (Ed.), Event-related potentials in children (pp. 455-461). Amsterdam: Elsevier Biomedical Press.

Kobal, G. (2003). Electrophysiological measurement of olfactory function. In R. L. Doty (Ed.), Handbook of olfaction and gustation (2nd ed, pp. 229-249). New York: Marcel Dekker.

Kobal, G., \& Hummel, T. (1998). Olfactory and intranasal trigeminal event-related potentials in anosmic patients. Laryngoscope, 108, 1033-1035.

Kopala, L., Clark, C., \& Hurwitz, T. A. (1989). Sex differences in olfactory function in schizophrenia. American Journal of Psychiatry, $146,1320-1322$.

Kopala, L., Good, K., Martzke, J., \& Hurwitz, T. (1995). Olfactory deficits in schizophrenia are not a function of task complexity. Schizophrenia Research, 17, 195-199.

Krüger, S., Frasnelli, J., Bräunig, P., \& Hummel, T. (2006). Increased olfactory sensitivity in euthymic patients with bipolar disorder with event-related episodes compared with patients with bipolar disorder without such episodes. Journal of Psychiatry \& Neuroscience, 31, 263270.

Laudien, J. H., Kuster, D., Sojka, B., Ferstl, R., \& Pause, B. M. (2006). Central odor processing in subjects experiencing helplessness. Brain Research, 1120, 141-150.

Laudien, J. H., Wencker, S., Ferstl, R., \& Pause, B. M. (2008). Context effects on odor processing: An event-related potential study. NeuroImage, 41, 1426-1436.

Lorig, T. S. (2000). The application of electroencephalographic techniques to the study of human olfaction: A review and tutorial. International Journal of Psychophysiology, 36, 91-104.

Lorig, T. S., Matia, D. C., Peszka, J., \& Bryant, D. N. (1996). The effects of active and passive stimulation on chemosensory event-related potentials. International Journal of Psychophysiology, 23, 199-205.

Lorig, T. S., Rigdon, M., \& Poor, A. (2006). Temporal pattern of odor administration alters hemispheric processing in humans. NeuroReport, 17, 231-234.
Lötsch, J., \& Hummel, T. (2006). The clinical significance of electrophysiological measures of olfactory function. Behavioral Brain Research, 170, 78-83.

Lundström, J. N., \& Hummel, T. (2006). Sex-specific hemispheric differences in cortical activation to a bimodal odor. Behavioral Brain Research, 166, 197-203.

Lundström, J. N., Seven, S., Olsson, M. J., Schaal, B., \& Hummel, T. (2006). Olfactory event-related potentials reflect individual differences in odor valence perception. Chemical Senses, 31, 705-711.

Mainland, J., \& Sobel, N. (2006). The sniff is part of the olfactory percept. Chemical Senses, 31, 181-196.

Malaspina, D., Perera, G. M., Lignelli, A., Marshall, R. S., Esser, P. D., Storer, S., et al. (1998). SPECT imaging of odor identification in schizophrenia. Psychiatry Research, 82, 53-61.

Martzke, J. S., Kopala, L. C., \& Good, K. P. (1997). Olfactory dysfunction in neuropsychiatric disorders: Review and methodological considerations. Biological Psychiatry, 42, 721-732.

Michel, C. M., Murray, M. M., Lantz, G., Gonzalez, S., Spinelli, L., \& Grave de Peralta, R. (2004). EEG source imaging. Clinical Neurophysiology, 115, 2195-2222.

Moberg, P. J., Agrin, R., Gur, R. E., Gur, R. C., Turetsky, B. I., \& Doty, R. L. (1999). Olfactory dysfunction in schizophrenia: A qualitative and quantitative review. Neuropsychopharmacology, 21, 325-340.

Moberg, P. J., Arnold, S. E., Doty, R. L., Gur, R. E., Balderston, C. C., Roalf, D. R., et al. (2006). Olfactory functioning in schizophrenia: Relationship to clinical, neuropsychological, and volumetric MRI measures. Journal of Clinical and Experimental Neuropsychology, 28, 1444-1461.

Morgan, C. D., Geisler, M. W., Covington, J. W., Polich, J., \& Murphy, C. (1999). Olfactory P3 in young and older adults. Psychophysiology, $36,281-287$.

Murphy, C., Morgan, C. D., Geisler, M. W., Wetter, S., Covington, J. W., Madowitz, M. D., et al. (2000). Olfactory event-related potentials and aging: Normative data. International Journal of Psychophysiology, 36, 133-145.

Nordin, S., Lötsch, J., Murphy, C., Hummel, T., \& Kobal, G. (2003). Circadian rhythm and desensitization in chemosensory event-related potentials in response to odorous and painful stimuli. Psychophysiology, 40, 612-619.

Nunez, P. L., \& Srinivasan, R. (2006). Electric fields of the brain: The neurophysics of EEG. New York: Oxford University Press.

Nurnberger, J. I. Jr., Blehar, M. C., Kaufmann, C. A., York Cooler, C., Simpson, S. G., Harkavy-Friedman, J., et al. (1994). Diagnostic interview for genetic studies. Rationale, unique features, and training. NIMH Genetics Initiative. Archives of General Psychiatry, 51, 849-859.

O'Donnell, B. F., Shenton, M. E., McCarley, R. W., Faux, S. F., Smith, R. S., Salisbury, D. F., et al. (1993). The auditory N2 component in schizophrenia: Relationship to MRI temporal lobe gray matter and to other ERP abnormalities. Biological Psychiatry, 34, 26-40.

Oldfield, R. C. (1971). The assessment and analysis of handedness: The Edinburgh inventory. Neuropsychologia, 9, 97-113.

Olofsson, J. K., Broman, D. A., Gilbert, P. E., Dean, P., Nordin, S., \& Murphy, C. (2006). Laterality of the olfactory event-related potential response. Chemical Senses, 31, 699-704.

Olofsson, J. K., Ericsson, E., \& Nordin, S. (2008). Comparison of chemosensory, auditory and visual event-related potential amplitudes. Scandinavian Journal of Psychology, 49, 231-237.

Olofsson, J. K., \& Nordin, S. (2004). Gender differences in chemosensory perception and event-related potentials. Chemical Senses, 29, 629-637.

Pause, B. M., Hellmann, G., Goder, R., Aldenhoff, J. B., \& Ferstl, R. (2008). Increased processing speed for emotionally negative odors in schizophrenia. International Journal of Psychophysiology, 70, 16-22.

Pause, B. M., \& Krauel, K. (2000). Chemosensory event-related potentials (CSERP) as a key to the psychology of odors. International Journal of Psychophysiology, 36, 105-122.

Pause, B. M., Krauel, K., Sojka, B., \& Ferstl, R. (1999). Is odor processing related to oral breathing? International Journal of Psychophysiology, 32, 251-260.

Pause, B. M., Raack, N., Sojka, B., Goder, R., Aldenhoff, J. B., \& Ferstl, R. (2003). Convergent and divergent effects of odors and emotions in depression. Psychophysiology, 40, 209-225. 
Pause, B. M., Sojka, B., Krauel, K., \& Ferstl, R. (1996). The nature of the late positive complex within the olfactory event-related potential (OERP). Psychophysiology, 33, 376-384.

Perrin, F., Pernier, J., Bertrand, O., \& Echallier, J. F. (1989). Spherical splines for scalp potential and current density mapping [Corrigenda EEG 02274, EEG Clin. Neurophysiol., 1990, 76, 565]. Electroencephalography and Clinical Neurophysiology, 72, 184-187.

Purdon, S. E., \& Flor-Henry, P. (2000). Asymmetrical olfactory acuity and neuroleptic treatment in schizophrenia. Schizophrenia Research, 44, 221-232.

Rombaux, P., Mouraux, A., Bertrand, B., Guerit, J. M., \& Hummel, T. (2006). Assessment of olfactory and trigeminal function using chemosensory event-related potentials. Neurophysiologie Clinique, 36, 5362.

Royet, J. P., \& Plailly, J. (2004). Lateralization of olfactory processes. Chemical Senses, 29, 731-745.

Seidman, L. J., Goldstein, J. M., Goodman, J. M., Koren, D., Turner, W. M., Faraone, S. V., et al. (1997). Sex differences in olfactory identification and Wisconsin Card Sorting performance in schizophrenia: Relationship to attention and verbal ability. Biological Psychiatry, 42, 104-115.

Sobel, N., Prabhakaran, V., Desmond, J. E., Glover, G. H., Goode, R. L., Sullivan, E. V., et al. (1998). Sniffing and smelling: Separate subsystems in the human olfactory cortex. Nature, 392, 282-286.

Stuck, B. A., Frey, S., Freiburg, C., Hormann, K., Zahnert, T., \& Hummel, T. (2006). Chemosensory event-related potentials in relation to side of stimulation, age, sex, and stimulus concentration. Clinical Neurophysiology, 117, 1367-1375.

Tateyama, T., Hummel, T., Roscher, S., Post, H., \& Kobal, G. (1998). Relation of olfactory event-related potentials to changes in stimulus concentration. Electroencephalography and Clinical Neurophysiology, $108,449-455$

Tenke, C. E., \& Kayser, J. (2001). A convenient method for detecting electrolyte bridges in multichannel electroencephalogram and event-related potential recordings. Clinical Neurophysiology, 112 , $545-550$.

Tenke, C. E., \& Kayser, J. (2005). Reference-free quantification of EEG spectra: Combining current source density (CSD) and frequency principal components analysis (fPCA). Clinical Neurophysiology, 116, 2826-2846

Tenke, C. E., Kayser, J., Shankman, S. A., Griggs, C. B., Leite, P., Stewart, J. W., et al. (2008). Hemispatial PCA dissociates temporal from parietal ERP generator patterns: CSD components in healthy adults and depressed patients during a dichotic oddball task. International Journal of Psychophysiology, 67, 1-16.

Tenke, C. E., Kayser, J., Stewart, J. W., \& Bruder, G. E. (2010). Novelty $\mathrm{P} 3$ reductions in depression: Characterization using principal components analysis (PCA) of current source density (CSD) waveforms. Psychophysiology, 47, 133-146.

Thesen, T., \& Murphy, C. (2001). Age-related changes in olfactory processing detected with olfactory event-related brain potentials using velopharyngeal closure and natural breathing. International Journal of Psychophysiology, 40, 119-127.
Turetsky, B. I., Kohler, C. G., Gur, R. E., \& Moberg, P. J. (2008). Olfactory physiological impairment in first-degree relatives of schizophrenia patients. Schizophrenia Research, 102, 220-229.

Turetsky, B. I., Moberg, P. J., Owzar, K., Johnson, S. C., Doty, R. L., \& Gur, R. E. (2003). Physiologic impairment of olfactory stimulus processing in schizophrenia. Biological Psychiatry, 53, 403-411.

Umbricht, D. S., Bates, J. A., Lieberman, J. A., Kane, J. M., \& Javitt, D. C. (2006). Electrophysiological indices of automatic and controlled auditory information processing in first-episode, recent-onset and chronic schizophrenia. Biological Psychiatry, 59, 762-772.

Wood, C. C., \& McCarthy, G. (1984). Principal component analysis of event-related potentials: Simulation studies demonstrate misallocation of variance across components. Electroencephalography and Clinical Neurophysiology, 59, 249-260.

Woods, S. W. (2003). Chlorpromazine equivalent doses for the newer atypical antipsychotics. Journal of Clinical Psychiatry, 64, 663-667.

Zatorre, R. J., Jones-Gotman, M., \& Rouby, C. (2000). Neural mechanisms involved in odor pleasantness and intensity judgments. NeuroReport, 11, 2711-2716.

\section{Supplementary Material}

The following supplementary material is available for this article (all figures provided in PDF format):

Figure A1. Grand mean olfactory ERP (in $\mu \mathrm{V}$ ) waveforms referenced to linked mastoids for 35 healthy adults and 32 schizophrenia patients at all 31 recording sites (averaged across intensity). Horizontal and vertical electrooculograms (EOG), which are shown at a smaller scale before blink correction, indicate no eye artifact concerns. Two prominent ERP components are labeled at sites T7 (N1) and Pz (P2).

Figure A2. Reference-free CSD $\left(\mu \mathrm{V} / \mathrm{cm}^{2}\right)$ waveforms for 35 healthy adults and 32 schizophrenia patients at all 31 recording sites (averaged across intensity). Two prominent CSD components are labeled at sites $\mathrm{T} 7$ ( $\mathrm{N} 1$ sink) and $\mathrm{Pz}(\mathrm{P} 2$ source).

Table A1. Means $( \pm S D)$ of N1 sink (factor 305)

Table A2. Means $( \pm S D)$ of $\mathrm{P} 2$ source (factor 630 )

This material is available as part of the online article from: http://www.blackwell-synergy.com/doi/10.1111/j.1469-8986. 2010.01013.x. (This link will take you to the article abstract).

Please note: Blackwell Publishing is not responsible for the content or functionality of any supplementary materials supplied by the authors. Any queries (other than missing material) should be directed to the corresponding author for the article.

(Received August 25, 2009; ACCEPTED November 13, 2009) 
Olfactory ERP generator patterns in schizophrenia

\section{Supplementary Material}

Table A1. Means ( \pm SD) of N1 sink (factor 305)

Sink activity at lateral centrotemporal sites (T7/8, C3/4, FC5/6, CP5/6)

\begin{tabular}{lcccrr} 
& Odor Intensity & \multicolumn{2}{c}{ High } & \multicolumn{2}{c}{ Low } \\
& Hemisphere & Left & Right & Left & Right \\
\hline Controls & Male & -0.95 & -0.99 & 0.07 & 0.17 \\
$(n=35)$ & $(n=18)$ & \pm 0.94 & \pm 0.92 & \pm 0.48 & \pm 0.58 \\
& Female & -1.50 & -1.35 & -0.19 & -0.08 \\
& $(n=17)$ & \pm 1.84 & \pm 1.26 & \pm 0.85 & \pm 0.70 \\
& Male & -0.91 & -0.98 & 0.05 & 0.15 \\
Patients & $(n=18)$ & \pm 0.97 & \pm 1.08 & \pm 0.57 & \pm 0.64 \\
& Female & -0.55 & -0.48 & -0.11 & 0.07 \\
& $(n=14)$ & \pm 0.97 & \pm 0.94 & \pm 0.80 & \pm 0.59 \\
\hline
\end{tabular}

Accompanying source activity at frontopolar sites

(Fp1/2)

\begin{tabular}{lcrrrr} 
& Odor Intensity & \multicolumn{2}{c}{ High } & \multicolumn{2}{c}{ Low } \\
& Hemisphere & \multicolumn{1}{c}{ Left } & Right & Left & \multicolumn{2}{c}{ Right } \\
\hline Controls & Male & 0.97 & 1.28 & -0.24 & 0.09 \\
$(n=35)$ & $(n=18)$ & \pm 0.87 & \pm 1.05 & \pm 0.70 & \pm 0.67 \\
& Female & 1.03 & 1.46 & -0.01 & 0.18 \\
& $(n=17)$ & \pm 1.80 & \pm 1.23 & \pm 1.48 & \pm 0.65 \\
Patients & Male & 0.33 & 0.70 & 0.01 & -0.05 \\
$(n=32)$ & $(n=18)$ & \pm 1.11 & \pm 0.74 & \pm 1.35 & \pm 1.17 \\
& Female & 0.36 & 0.29 & -0.09 & 0.35 \\
& $(n=14)$ & \pm 1.08 & \pm 0.85 & \pm 1.13 & \pm 1.59 \\
\hline
\end{tabular}


Table A2. Means $( \pm \mathrm{SD})$ of P2 source (factor 630 )

Source activity at medial-lateral centroparietal sites

(P3/4, P7/8, CP5/6, C3/4)

\begin{tabular}{ccrrrr} 
& Odor Intensity & \multicolumn{2}{c}{ High } & \multicolumn{2}{c}{ Low } \\
& Hemisphere & \multicolumn{1}{c}{ Left } & Right & \multicolumn{1}{c}{ Left } & \multicolumn{2}{c}{ Right } \\
\hline Controls & Male & 0.67 & 0.73 & 0.08 & 0.13 \\
$(n=35)$ & $(n=18)$ & \pm 0.81 & \pm 0.91 & \pm 0.63 & \pm 0.62 \\
& Female & 0.94 & 1.08 & 0.38 & 0.44 \\
& $(n=17)$ & \pm 1.06 & \pm 0.95 & \pm 0.79 & \pm 0.71 \\
Patients & Male & 0.42 & 0.42 & 0.15 & 0.25 \\
$(n=32)$ & $(n=18)$ & \pm 0.83 & \pm 0.80 & \pm 0.62 & \pm 0.57 \\
& & & & 0.60 & 0.33 \\
& Female & 0.42 & & 0.60 & \pm 0.68 \\
\hline
\end{tabular}

Accompanying sink activity at lateral frontotemporal sites (FT9/10, F7/8)

\begin{tabular}{cccccc} 
& Odor Intensity & \multicolumn{2}{c}{ High } & \multicolumn{2}{c}{ Low } \\
& Hemisphere & Left & Right & Left & Right \\
\hline Controls & Male & -0.62 & -0.69 & -0.25 & -0.36 \\
$(n=35)$ & $(n=18)$ & \pm 0.92 & \pm 0.93 & \pm 0.82 & \pm 0.67 \\
& Female & -1.28 & -1.62 & -0.73 & -0.95 \\
& $(n=17)$ & \pm 0.85 & \pm 0.89 & \pm 0.66 & \pm 0.67 \\
& Male & -0.48 & -0.70 & -0.24 & -0.41 \\
$(n=32)$ & $(n=18)$ & \pm 0.95 & \pm 0.90 & \pm 0.58 & \pm 0.77 \\
& Female & -0.84 & -0.97 & -0.56 & -0.66 \\
& $(n=14)$ & \pm 1.07 & \pm 0.94 & \pm 0.68 & \pm 0.90 \\
\hline
\end{tabular}


Figure A1. Grand mean olfactory ERP $[\mu \mathrm{V}]$ waveforms referenced to linked mastoids for 35 healthy adults and 32 schizophrenia patients at all 31 recording sites (averaged across intensity). Horizontal and vertical electrooculograms (EOG), which are shown at a smaller scale before blink correction, indicate no eye artifact concerns. Two prominent ERP components are labeled at sites $\mathrm{T} 7(\mathrm{~N} 1)$ and $\mathrm{Pz}(\mathrm{P} 2)$.
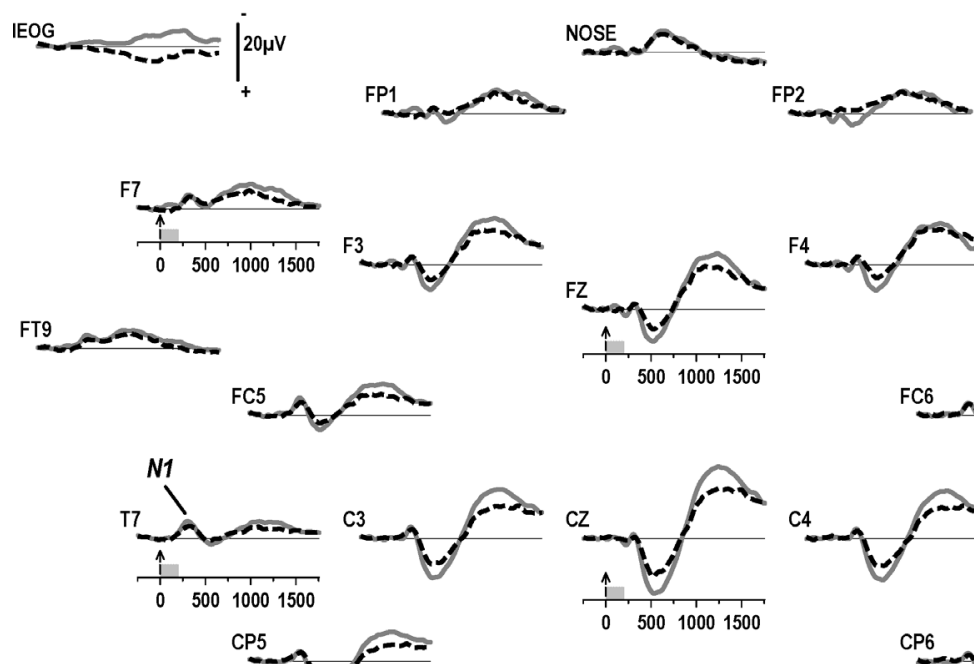

TP9
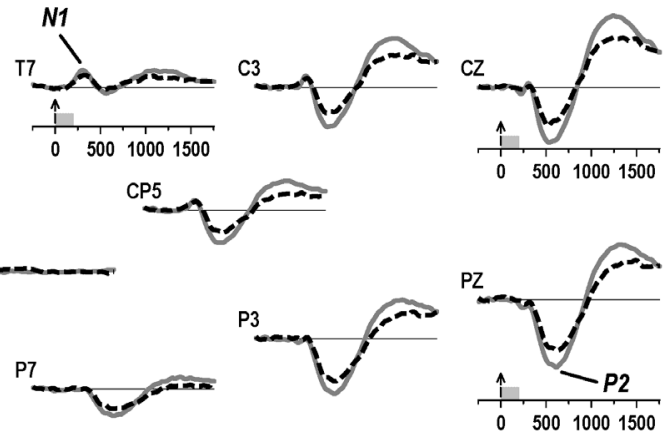

P9
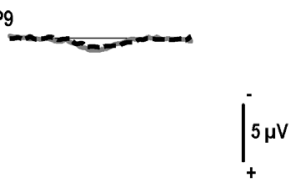

CP6
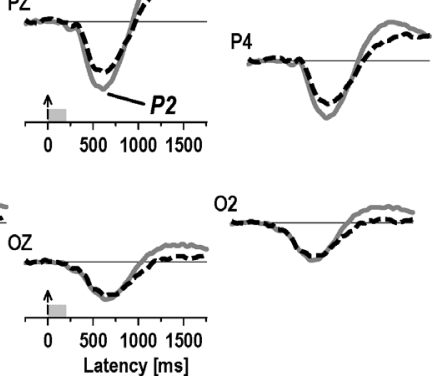
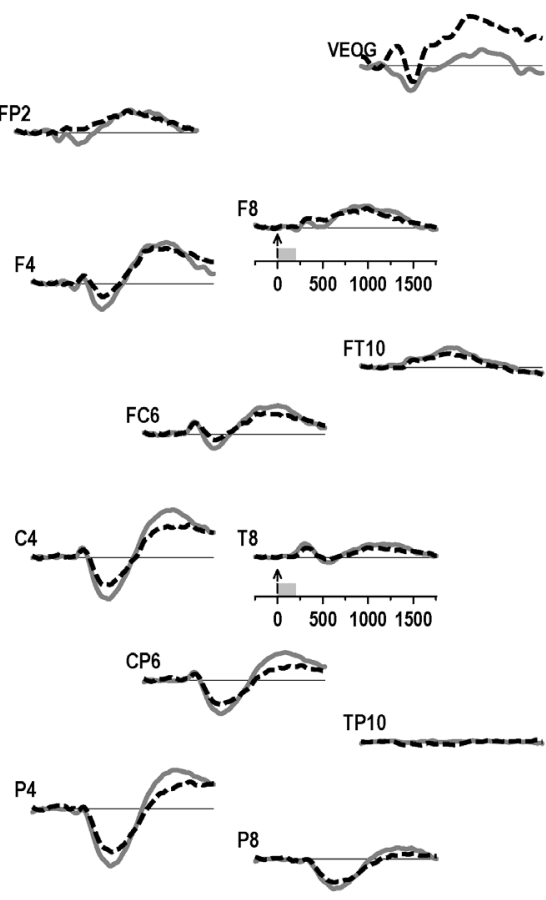

P10
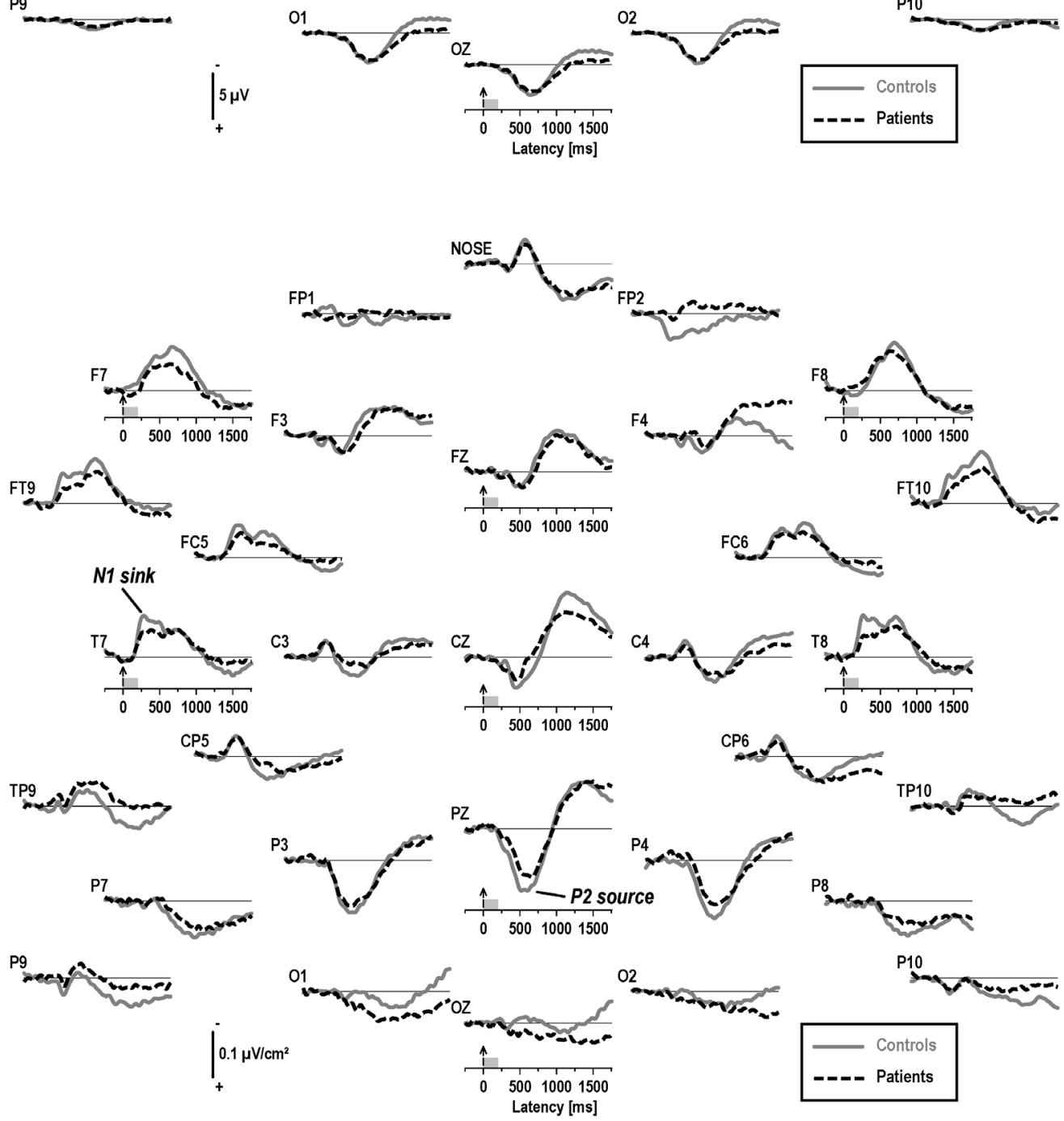

Figure A2. Reference-free $\mathrm{CSD}\left[\mu \mathrm{V} / \mathrm{cm}^{2}\right]$ waveforms for 35 healthy adults and 32 schizophrenia patients at all 31 recording sites (averaged across intensity). Two prominent CSD components are labeled at sites T7 (N1 sink) and $\mathrm{Pz}$ (P2 source). 